Liu, Wenxi

Guan, Huiren

Zhou, Qidou

Lou,Jingjun

http://dx.doi.org/10.21278/brod72204

\title{
STUDY ON STRUCTURAL-ACOUSTIC CHARACTERISTICS OF CYLINDRICAL SHELL BASED ON WAVENUMBER SPECTRUM ANALYSIS METHOD
}

UDC 629.5.015.5:629.5.015.6

Original scientific paper

\begin{abstract}
Summary
By the finite element method, the structural vibration response is calculated under the action of the axial exciting force and the moment with different distribution form, and then the transfer function of the mean square normal velocity is analyzed. The wavenumber spectrum analysis method is used to separate and quantify the shell vibration in the wavenumber domain, and then the relation between the structural vibration characteristics and the structural wavelength is summarized. It is concluded that the structural vibration and radiated noise can be reduced under the symmetric action of axial exciting force and the moment. Based on the above conclusion, a symmetrical thrust bearing supporting system is designed and the stiffness of the supporting structure in the axial direction is controlled by selecting suitable size of structural members, therefore, the structural vibration and radiated noise of the submarine is reduced significantly.
\end{abstract}

Key words: $\quad$ cylindrical shell; wavenumber spectrum; structural vibration; thrust bearing supporting system; radiated noise

\section{Introduction}

In the low velocity case, the structural vibration and radiated noise of the submarine is a matter of great concern. The cylindrical shell is the main component of the submarine [1]. It is of great significance to study the acoustic characteristics of the cylindrical shell for the control of the structural vibration and radiated noise of submarine.

So far, scholars from home and abroad have done a lot of researches on the structuralacoustic characteristics of the cylindrical shell, and they mainly concentrate on two aspects, one is the predicting method of radiated noise, another is the structural-acoustic optimization design.

In the study of the predicting method of radiated noise, the vibro-acoustic coupling model of the cylindrical shell was established by the analytical method and the numerical method to obtain the structural vibration and acoustic characteristics. SKIDAN et al. [2, 3] 
established the vibro-acoustic coupling model by the modal expansion method. CHANG et al. [4-6] established a coupled structure-acoustics-fluid equation by making use of the Flügge shell theory, in which the frame, longitudinal stiffener, supporting board, rib board were treated as the force on the shell.

Merz et al. [7, 8] made use of the finite element method and the boundary element method to establish the fluid-structure coupling numerical model of the cylindrical shell, and carried out the numerical analysis of the vibration and radiated noise of the submarine on the action of exciting force. Based on the wave propagation and image-source method, Wang et al. [9] analyzed the natural vibration characteristics of the cylindrical shell in shallow water. Combining the wavenumber analysis method with the image method, Ye et al. [10, 11] analyzed the characteristics of the vibration and radiated noise of the cylindrical shells when there existed a free liquid surface or a rigid wall surface. Based on the potential flow theory, KWAK [12] completed the study of the free vibration analysis of a cylindrical shell by adding the attached water mass into the free vibration equation of the cylindrical shell in the form of matrix. Yang et al. [13] made use of the Donnel shell equation to describe the vibration of a double-layer cylindrical shell, in which the effect of ring ribs, solid rib plates and water medium on the shell was expressed in the form of additional impedance, and analyzed the influence of the exciting source performance on the characteristics of the noise transmission between the inner shell and the outer shell.

In the study of structural-acoustic optimization design, Lee et al. [14] divided the orthogonal and equally spaced stiffened cylindrical shells into two kind of structures, that is to say, equally spaced frames and equally spaced longitudinal stiffeners, and the propagation law of the structural wave and the vibration characteristics of the structure were analyzed. Mecitoglu [15] studied the effect of the size of frames and longitudinal stiffeners on the fundamental frequency of the cone shells with orthogonal equal-spacing stiffener and found that the influence of the frames on the fundamental frequency of the cone shells was greater than that of the longitudinal stiffener. Photiadis [16] studied the vibration characteristics of an infinitely long non-periodic cylindrical shell subjected to fluid load in the middle frequency band by the method of the equal-effect force and moment. By the finite element method, Marcus et al. [17] analyzed the vibration characteristics of two type of irregular cylindrical shell structures, one with unequal-spacing ribs, and another with equal-spacing ribs whose thickness is unequal. Bai et al. [3] analyzed the influence of the parameters, such as solid ribs, ring ribs, characteristics of the excitation, etc. on the acoustic properties of cylindrical shell. Zhou et al. [5, 6] compared the influence of the connecting forms between the inner shell and the outer shell on the acoustic properties of double-layer cylindrical shells. Liu et al. [8] studied the influence of the structural parameters, such as cabin length, frame spacing, shell plate thickness, rib cross-sectional dimensions, etc., on the characteristics of vibration and radiated noise of cylindrical shell.

To summary, the train of thought of the structural-acoustic optimization design is adopted: take the structural parameters as the variables, enumerate a variety of structural forms of cylindrical shell, and then calculate the total vibration and radiated noise of the cylindrical shell, by the comparing analysis, obtain the optimal plan. The study in this paper is based on the above research, and the difference with the above researches is that the wavenumber spectrum analysis method was used to separate and quantify the waveform of the shell vibration in the wavenumber domain. The relation between the structural vibration level and the structural wavelength was analyzed, therefore, the waveform component which contributed a lot to the total vibration was obtained, and a reasonable mode of the exciting force was obtained. On the basis of the above conclusion, a design method of the thrust bearing supporting structure was developed. 


\section{Wavenumber spectrum analysis theory of cylindrical shell}

\subsection{Vibration waveform separation}

To transform the vibration response of cylindrical shell from the spatial domain into the wavenumber domain, the vibration response field with finite length in the axial direction is extended to infinite. The assumption that there are infinite cylindrical baffles at the two ends of the finite shell [18] leads to the expression of the vibration response as:

$$
w(x, \theta)=\left\{\begin{array}{cc}
w_{\mathrm{R}}+\mathrm{j} w_{\mathrm{I}}, & x \in[0, l] \\
0, & x \notin[0, l]
\end{array}\right.
$$

where $x$ and $\theta$ are the axial and circumferential coordinates in the cylindrical coordinate system respectively; $w_{\mathrm{R}}$ and $w_{\mathrm{I}}$ are the real and imaginary parts of the normal displacement $w$ of the shell; $l$ is the length of cylindrical shell; $\mathrm{j}=\sqrt{-1}$. The Fourier series expansion of $w_{\mathrm{R}}$ and $w_{\mathrm{I}}$ is carried out in the circumferential direction, and the Fourier transform is carried out in the axial direction [19]:

$$
\left\{\begin{aligned}
w_{\mathrm{R}}= & \frac{1}{2 \pi} \sum_{n=0}^{\infty}\left\{\int _ { - \infty } ^ { + \infty } \left[A_{n}^{\mathrm{R}}\left(k_{x}\right) \cos n \theta \mathrm{e}^{\mathrm{j} k_{x} x}\right.\right. \\
& \left.\left.+B_{n}^{\mathrm{R}}\left(k_{x}\right) \sin n \theta \mathrm{e}^{\mathrm{j} k_{x} x}\right] \mathrm{~d} k_{x}\right\} \\
w_{\mathrm{I}}= & \frac{1}{2 \pi} \sum_{n=0}^{\infty}\left\{\int _ { - \infty } ^ { + \infty } \left[A_{n}^{\mathrm{I}}\left(k_{x}\right) \cos n \theta \mathrm{e}^{\mathrm{j} k_{x} x}\right.\right. \\
& \left.\left.+B_{n}^{\mathrm{I}}\left(k_{x}\right) \sin n \theta \mathrm{e}^{\mathrm{j} k_{x} x}\right] \mathrm{~d} k_{x}\right\}
\end{aligned}\right.
$$

where $k_{x}$ and $n$ are the axial and circumferential wavenumber, and the wavenumber of a single structure wave component is expressed as $\left(k_{x}, n\right)$. Equation (2) shows that the vibration response field of the cylindrical shell is decomposed into a superposition of simple travelling waves with different axial and circumferential wavenumber. $A_{n}^{\mathrm{R}}\left(k_{x}\right), B_{n}^{\mathrm{R}}\left(k_{x}\right), A_{n}^{\mathrm{I}}\left(k_{x}\right)$ and $B_{n}^{\mathrm{I}}\left(k_{x}\right)$ are the amplitude of the wave whose wavenumber is marked as $\left(k_{x}, n\right)$.

\subsection{Vibration power wavenumber spectrum}

The square of the normal velocity of the shell in equation (1) is integrated on the surface of the cylindrical shell, and the vibration power $E_{\mathrm{v}}^{\mathrm{t}}$ expressed by normal velocity on the surface of the whole cylindrical shell is obtained, which is called the normal velocity vibration power for short.

$$
\begin{aligned}
E_{\mathrm{v}}^{\mathrm{t}}= & \frac{\rho_{0} c_{0} \omega^{2}}{2} \int_{0}^{l} \int_{0}^{2 \pi}\left[\left|w_{\mathrm{R}}\right|^{2}\right. \\
& \left.+\left|w_{\mathrm{I}}\right|^{2}\right]\left.r \mathrm{~d} \theta \mathrm{d} x\right|_{r=a}
\end{aligned}
$$

Where $a$ is the radius of the cylindrical shell; $\rho_{0}$ is the density of the fluid; $c_{0}$ is the sound velocity of the fluid. The multiplier of the acoustic impedance $\rho_{0} c_{0}$ can transform the equation dimension into the power unit, which does not change the frequency characteristics of the vibration power. The fluid in this paper refers to the air. Combining the equation (2) 
and the equation (3), and by using the Parseval equation, the equation (3) can be simplified into [19]:

$$
E_{\mathrm{v}}^{\mathrm{t}}=\left\{\begin{array}{l}
a \rho_{0} c_{0} \omega^{2} \int_{0}^{+\infty}\left[\left|A_{n}^{\mathrm{R}}\left(k_{x}\right)\right|^{2}\right. \\
\left.+\left|A_{n}^{\mathrm{I}}\left(k_{x}\right)\right|^{2}\right] \mathrm{d} k_{x} \quad, n=0 \\
a \rho_{0} c_{0} \omega^{2} \int_{0}^{+\infty}\left[\left|A_{n}^{\mathrm{R}}\left(k_{x}\right)\right|^{2}\right. \\
\left.+\left|A_{n}^{\mathrm{I}}\left(k_{x}\right)\right|^{2}\right] \mathrm{d} k_{x} \\
+\sum_{n=1}^{\infty} \frac{a \omega^{2} \rho_{0} c_{0}}{2} \int_{0}^{+\infty}\left[\left|A_{n}^{\mathrm{R}}\left(k_{x}\right)\right|^{2}\right. \\
+\left|A_{n}^{\mathrm{I}}\left(k_{x}\right)\right|^{2}+\left|B_{n}^{\mathrm{R}}\left(k_{x}\right)\right|^{2} \\
\left.+\left|B_{n}^{\mathrm{I}}\left(k_{x}\right)\right|^{2}\right] \mathrm{d} k_{x} \quad, n \neq 0
\end{array}\right.
$$

The total normal velocity vibration power of the shell can be expressed as the superposition of the normal velocity vibration power of the wave component with the wavenumber $\left(k_{x}, n\right)$ :

$$
E_{\mathrm{v}}^{\mathrm{t}}=\sum_{n=0}^{\infty} \int_{0}^{+\infty} E_{\mathrm{v}}\left(n, k_{x}\right) \mathrm{d} k_{x}, k_{x} \geq 0
$$

Therefore, according to the equations (4) and (5), the normal velocity vibration power $E_{\mathrm{v}}\left(n, k_{x}\right)$ of a single simple travelling wave with the wavenumber $\left(k_{x}, n\right)$ can be acquired:

$$
E_{\mathrm{v}}\left(n, k_{x}\right)=\left\{\begin{array}{l}
a \rho_{0} c_{0} \omega^{2}\left(\left|A_{n}^{\mathrm{R}}\left(k_{x}\right)\right|^{2}\right. \\
\left.+\left|A_{n}^{\mathrm{I}}\left(k_{x}\right)\right|^{2}\right), n=0 \\
\frac{a \rho_{0} c_{0}}{2} \omega^{2}\left(\left|A_{n}^{\mathrm{R}}\left(k_{x}\right)\right|^{2}\right. \\
+\left|A_{n}^{\mathrm{I}}\left(k_{x}\right)\right|^{2}+\left|B_{n}^{\mathrm{R}}\left(k_{x}\right)\right|^{2} \\
+\left|B_{n}^{\mathrm{I}}\left(k_{x}\right)\right|^{2}, n \neq 0
\end{array}\right.
$$

For the wavenumber $n$, the normal velocity vibration power (in the following text, called as $n$ order vibration) is 


$$
\begin{aligned}
E_{\mathrm{v}}^{n}= & \int_{0}^{+\infty} E_{\mathrm{v}}\left(n, k_{x}\right) \mathrm{d} k_{x} \\
& =\left\{\begin{array}{l}
a \rho_{0} c_{0} \omega^{2} \int_{0}^{+\infty}\left[\left|A_{n}^{\mathrm{R}}\left(k_{x}\right)\right|^{2}\right. \\
\left.+\left|A_{n}^{\mathrm{I}}\left(k_{x}\right)\right|^{2}\right] \mathrm{d} k_{x} \quad, n=0 \\
\frac{a \rho_{0} c_{0} \omega^{2}}{2} \int_{0}^{+\infty}\left[\left|A_{n}^{\mathrm{R}}\left(k_{x}\right)\right|^{2}\right. \\
+\left|A_{n}^{\mathrm{I}}\left(k_{x}\right)\right|^{2}+\left|B_{n}^{\mathrm{R}}\left(k_{x}\right)\right|^{2} \\
\left.+\left|B_{n}^{\mathrm{I}}\left(k_{x}\right)\right|^{2}\right] \mathrm{d} k_{x}, n \neq 0
\end{array}\right.
\end{aligned}
$$

\section{Cylindrical shell axial Wavenumber spectrum analysis}

Table 1 lists the main structural parameters of cylindrical shell, with a T-shaped frame section (Fig. 1). The framed cylindrical shell was modelled by the finite element method. Specifically, the shell was simulated by surface elements, while the frames and other stiffeners were simulated by beam elements; along the longitudinal direction of the submarine, one frame interval contains at least four rows of elements and five nodes to ensure the simulation of a complete waveform between frames, and the model was set in a free state.

Table 1 Structure parameters of cylindrical shell

\begin{tabular}{|c|c|}
\hline Parameter & Value \\
\hline Cylindrical shell length $(\mathrm{m})$ & 60 \\
\hline Cylindrical shell diameter $(\mathrm{m})$ & 7.5 \\
\hline Shell thickness of cylindrical shell $(\mathrm{m})$ & 0.032 \\
\hline Plate thickness of spherical bulkhead at stern $(\mathrm{m})$ & 0.02 \\
\hline Frame interval $(\mathrm{m})$ & 0.6 \\
\hline Flange height $h(\mathrm{~m})$ & 0.12 \\
\hline Web height $w(\mathrm{~m}) \mathrm{m}$ & 0.3 \\
\hline Flange thickness $t_{1}(\mathrm{~m})$ & 0.03 \\
\hline Web thickness $t_{2}(\mathrm{~m})$ & 0.02 \\
\hline
\end{tabular}

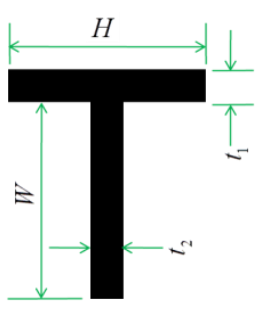

Fig. 1 Frame section

The cylindrical shell and the internal structure are symmetrical along the up-and-down direction and the left-and-right direction. The all finite element model is shown in Fig. 2, and the two ends are closed with spherical bulkheads. The internal structure is shown in Fig. 3, and the bulkhead structure is shown in Fig. 4. 


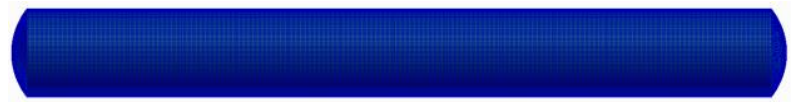

Fig. 2 Finite element model of the pressure shell
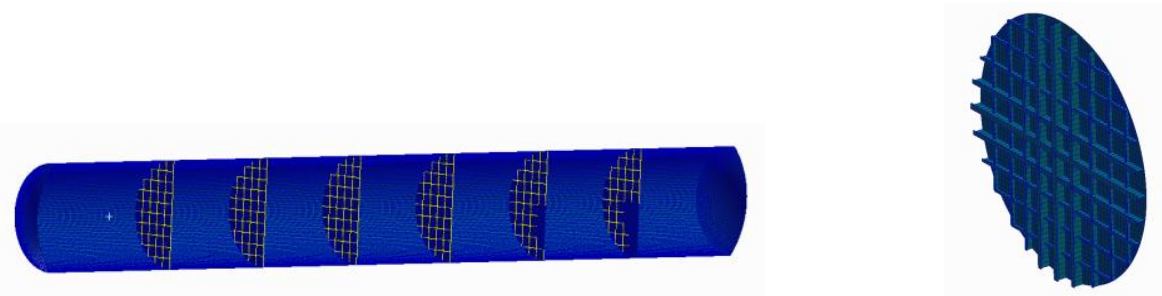

Fig. 3 Finite element model of inner structures

Fig. 4 Finite element model of inner bulkhead Table 2 shows five calculation cases.

Table 2 Calculation cases

\begin{tabular}{|c|l|}
\hline Case number & \multicolumn{1}{c|}{ Detail } \\
\hline 1 & Axial exciting force acting on the structure near the bottom part \\
\hline 2 & Axial exciting force acting on the bottom part \\
\hline 3 & Axial exciting force acting on the cross-section symmetrically \\
\hline 4 & Moment acting on the bottom part \\
\hline 5 & Moment acting on the cross-section symmetrically \\
\hline
\end{tabular}

Fig. 5 shows case 1 , and the magnitude of the axial exciting force is $1 \mathrm{~N}$.

Fig. 6 shows case 2, and the magnitude of the axial exciting force is $1 \mathrm{~N}$.

Fig. 7 shows case 3, the longitudinal exciting force acts on the points A, B, C, and D, and the applied force at each point is $1 / 4$ in magnitude, which is equivalent to the uniform distribution of case 1 exciting force at the four points

Fig. 8 shows case 4 , and the magnitude of the exciting moment is $1 \mathrm{~N} \cdot \mathrm{m}$.

Fig. 9 shows case 5 , and the exciting moment acts on the points $\mathrm{A}, \mathrm{B}, \mathrm{C}$, and $\mathrm{D}$, and the applied moment at each point is $1 / 4$ in magnitude, which is equivalent to the uniform distribution of case 4 moment at the four points.

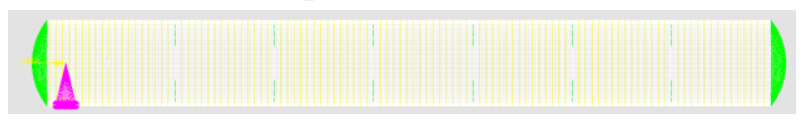

Fig. 5 Case 1

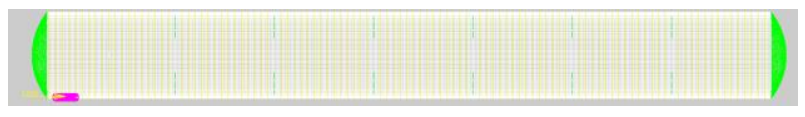

Fig. 6 Case 2

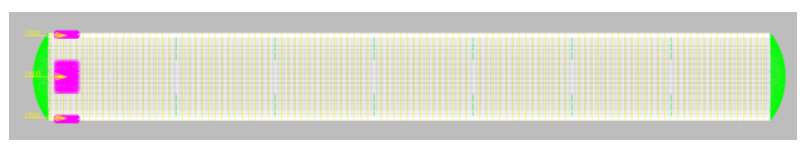

Fig. 7 Case 3

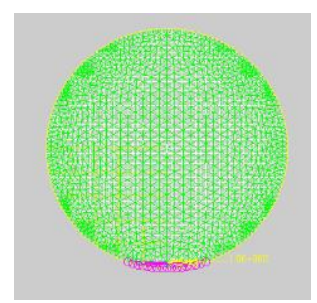

Fig. 8 Case 4

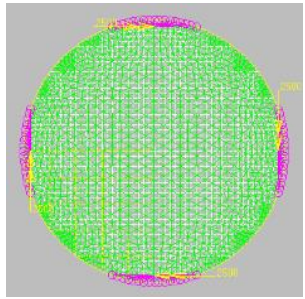

Fig. 9 Case 5 
In the following section, case 1 was taken as an example to illustrate the process of wavenumber spectrum analysis.

Fig. 10 shows the total normal velocity vibration power of the shell obtained by equation (4).

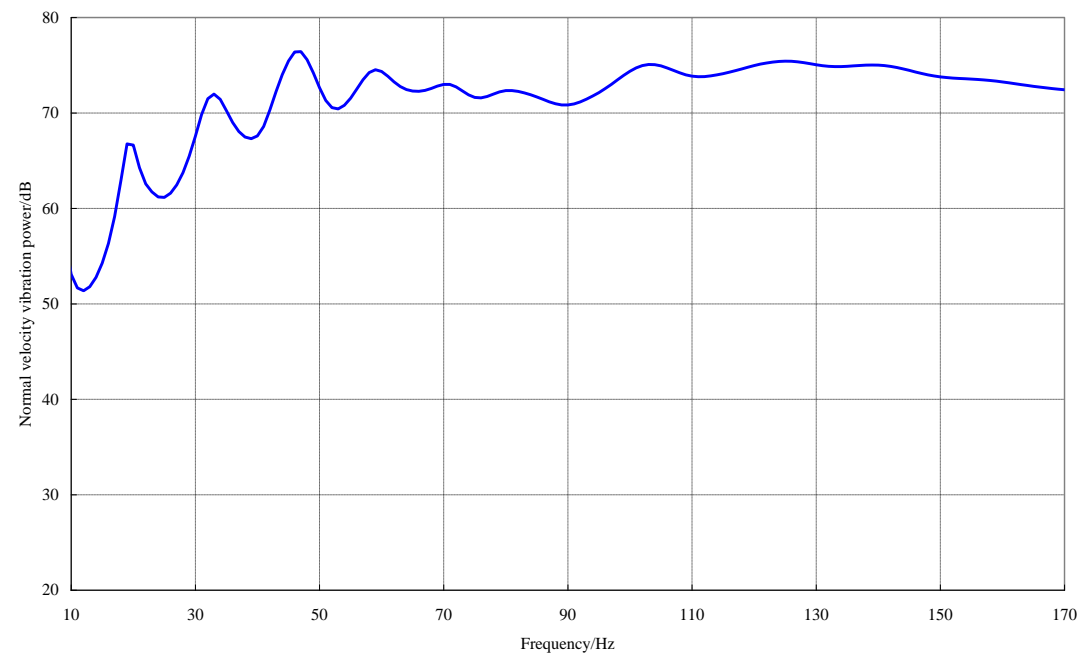

Fig. 10 Normal velocity vibration power for case 1

There are obvious peaks at the frequencies of 19, 33 and $46 \mathrm{~Hz}$. Among the three frequencies, the peak at $46 \mathrm{~Hz}$ is maximum. The complex vibration of the cylindrical shell can be decomposed into the superposition of the various regular travelling waves. By quantifying the contribution of each wave component to the total vibration of the shell, the mechanism of vibration was studied to find the cause for the peak value, and then the corresponding measures was taken to control the vibration of the cylindrical shell.

\subsection{Vibration characteristics of the cylindrical shell in the circumferential direction}

The vibration characteristics of the cylindrical shell was analyzed in the circumferential direction. By the wavenumber spectrum analysis method, the normal velocity vibration power of each circumferential order of the cylindrical shell was calculated according to equation (7), and the result was shown in Fig. 11.

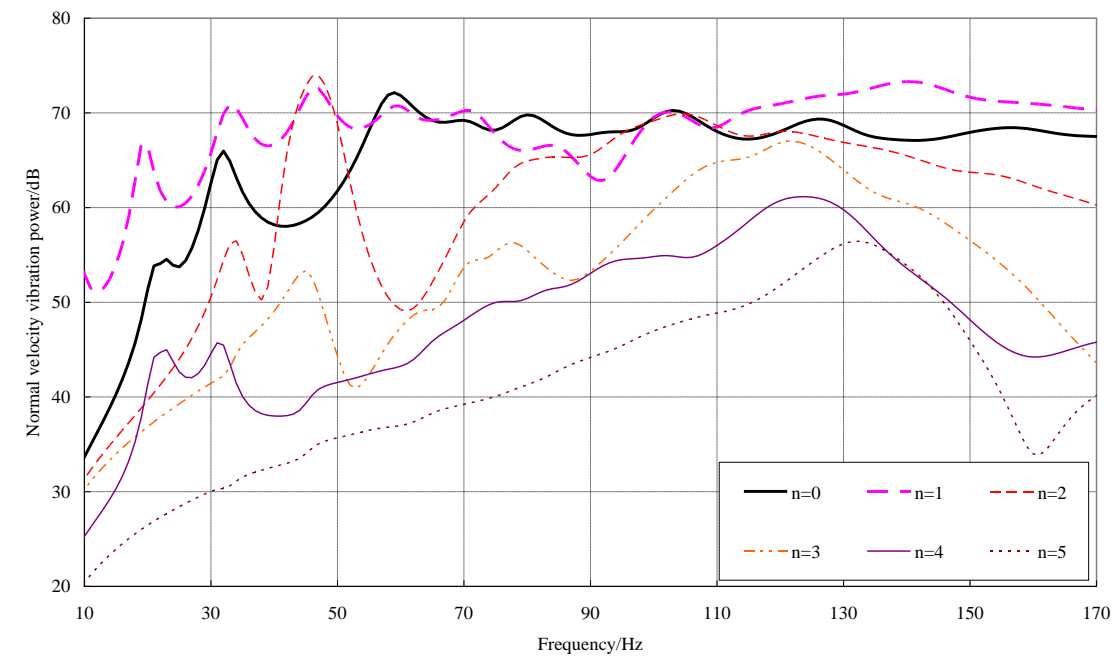

Fig. 11 Normal velocity vibration power corresponding to $n=0,1,2,3,4,5$ for case 1 
Fig. 11 shows the frequency curves of the $n=0,1,2,3,4,5$ order normal velocity vibration power of the shell under case 1 . When the frequency of the exciting force is less than $170 \mathrm{~Hz}$, except for the vicinity of $46 \mathrm{~Hz}$, the $n=1$ order vibration is the main vibration mode; while in the vicinity of $46 \mathrm{~Hz}$, the $n=1$ and 2 order vibration is the main vibration mode. Because of the action of the axial force, a moment is induced at the connecting part between the base and the cylindrical shell, therefore, the $n=2$ order bending vibration is induced in the circumferential direction.

\subsection{Vibration characteristics of cylindrical shell in the axial direction}

Axial wavenumber spectrum analysis of the vibration of the shell was carried out at the typical frequencies. According to Fig. 10, there are obvious peaks at the frequencies of 19, 33, and $46 \mathrm{~Hz}$, so that the three frequencies are typical frequencies.

According to Fig. 11, at typical frequency of $19 \mathrm{~Hz}$, because the $\mathrm{n}=1$ order vibration of the shell is the main vibration mode, the wavenumber spectrum of the $n=1$ order normal velocity vibration power of the cylindrical shell was calculated by equation (6), and then made axial wavenumber spectrum analysis.

Fig. 12 shows the wavenumber spectrum of the normal velocity vibration power of $n=1$ order vibration of the shell at the typical frequency of $19 \mathrm{~Hz}$ under case 1 , where $12 l k_{x} / \pi$ is the axial dimensionless wavenumber of the shell; $l$ is the axial length of the shell; $k_{x}$ is the axial wavenumber of the shell, $k_{x}=2 \pi / \lambda, \lambda$ is the structural wavelength.

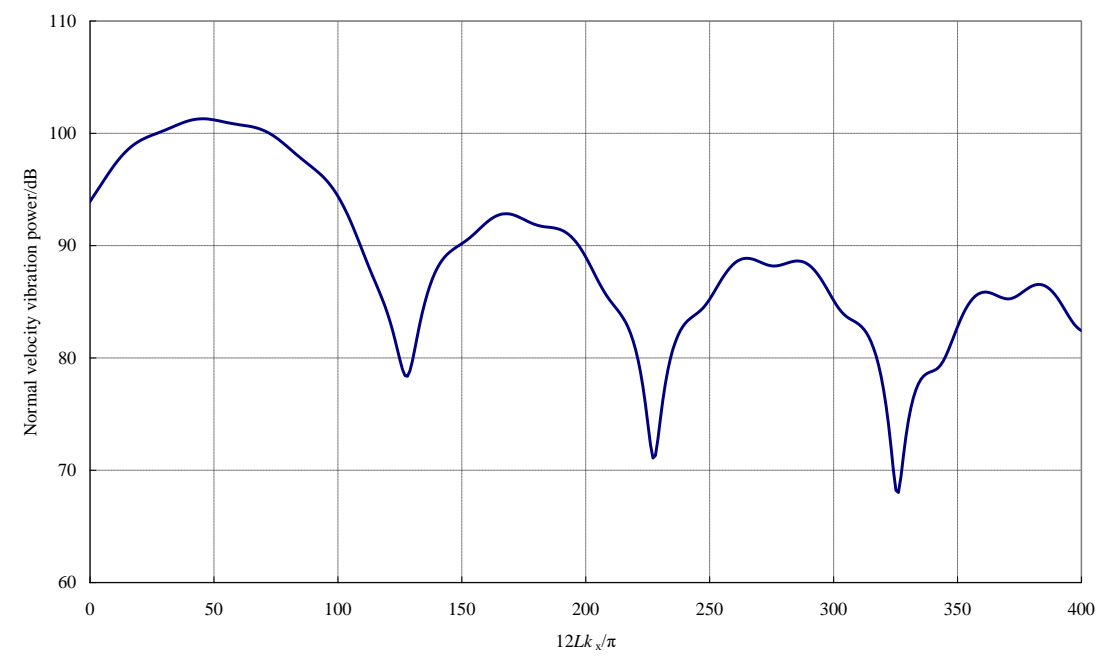

Fig. 12 Normal velocity vibration power wavenumber spectrum in typical frequencies $19 \mathrm{~Hz}$ corresponding to $\mathrm{n}=1$ for case 1

It can be seen from Fig. 12 that the dimensionless wavenumber of the main peak of the wavenumber spectrum is 45 , therefore, the corresponding axial wavelength of the structure is approximately equal to one half of the length of the cylindrical shell $(\lambda / l=0.53)$, and the characteristic can also be seen from the vibration mode of the shell, as shown in Fig. 13, where Fig. 13 (a) shows the axial vibration mode and Fig. 13(b) shows the circumferential vibration mode. 


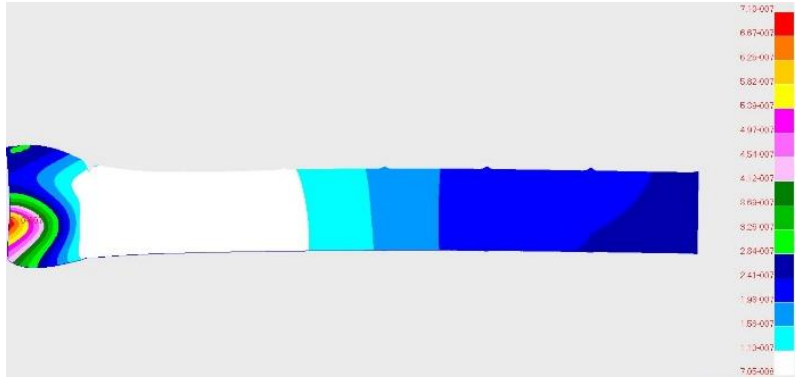

(a)

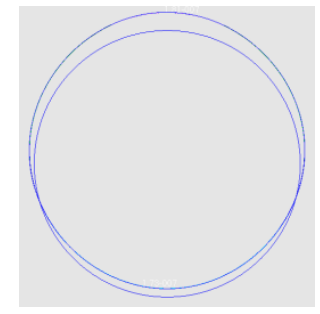

(b)

Fig. 13 Vibration model in $19 \mathrm{~Hz}$ for case 1

(a) Axial vibration mode; (b) Circumferential vibration mode

Fig. 14 shows the wavenumber spectrum of the normal velocity vibration power of $n=1$ order vibration of the shell at the typical frequency of $33 \mathrm{~Hz}$ under case 1.

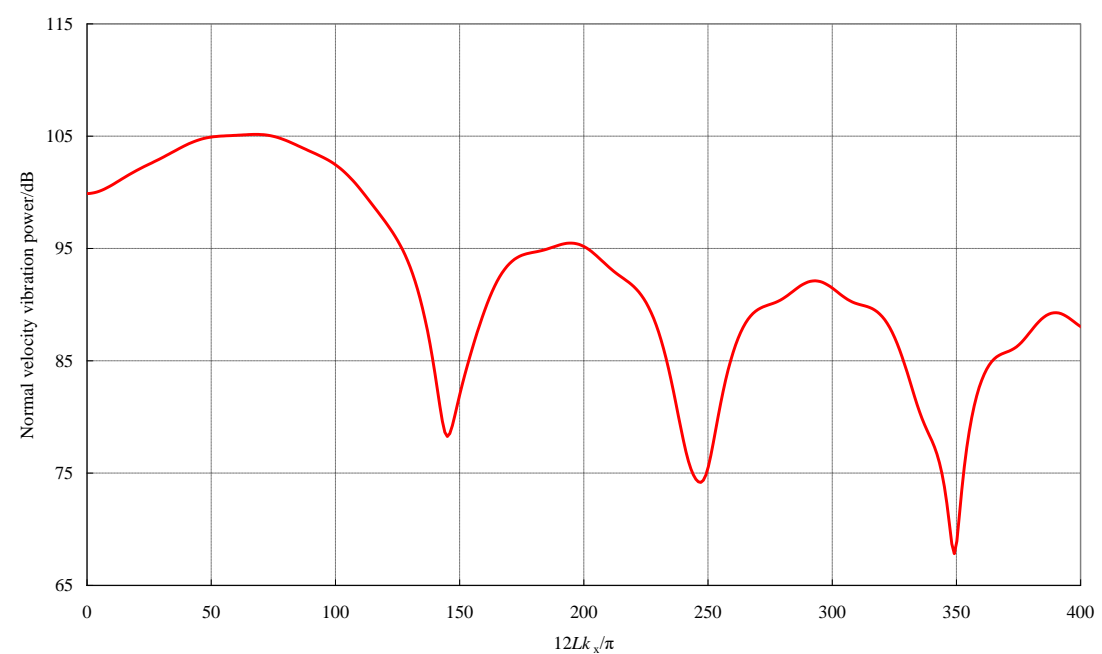

Fig. 14. Normal velocity vibration power wavenumber spectrum in typical frequencies $33 \mathrm{~Hz}$ corresponding to $\mathrm{n}=1$ for case 1

It can be seen from Fig. 14 that the dimensionless wavenumber of the main peak of the wavenumber spectrum is 54, therefore, the axial wavelength of the structure is approximately equal to one half of the length of the cylindrical shell $(\lambda / l=0.44)$, and the characteristic can also be seen from the vibration mode of the shell, as shown in Fig. 15, where Fig. 15(a) shows the axial vibration mode and Fig. 15(b) shows the circumferential vibration mode.

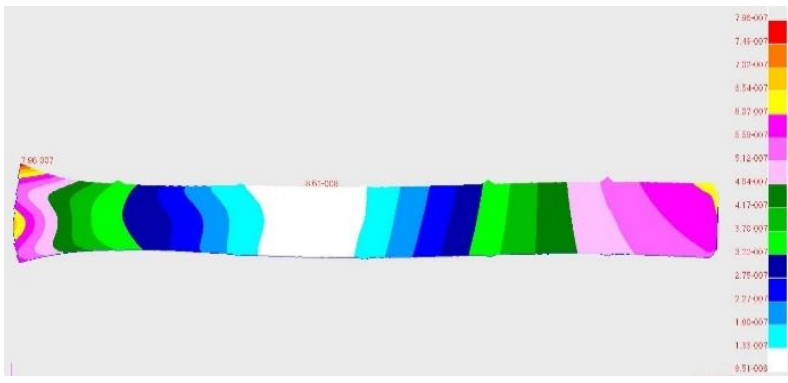

(a)

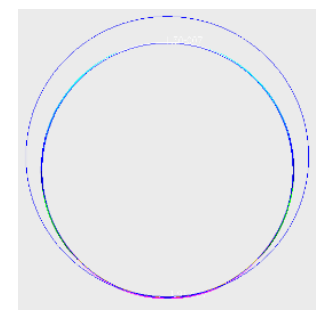

(b)

Fig. 15 Vibration model in $33 \mathrm{~Hz}$ for case 1

(a) Axial vibration mode; (b) Circumferential vibration mode

According to Fig. 11, at typical frequency of $46 \mathrm{~Hz}$, because $n=1$ and 2 order vibration is the main vibration mode under case 1 , the wavenumber spectrum (Fig. 16) of the normal 
velocity vibration power of $n=1$ and 2 order vibration of the shell was calculated and carried out axial wavenumber spectrum analysis.

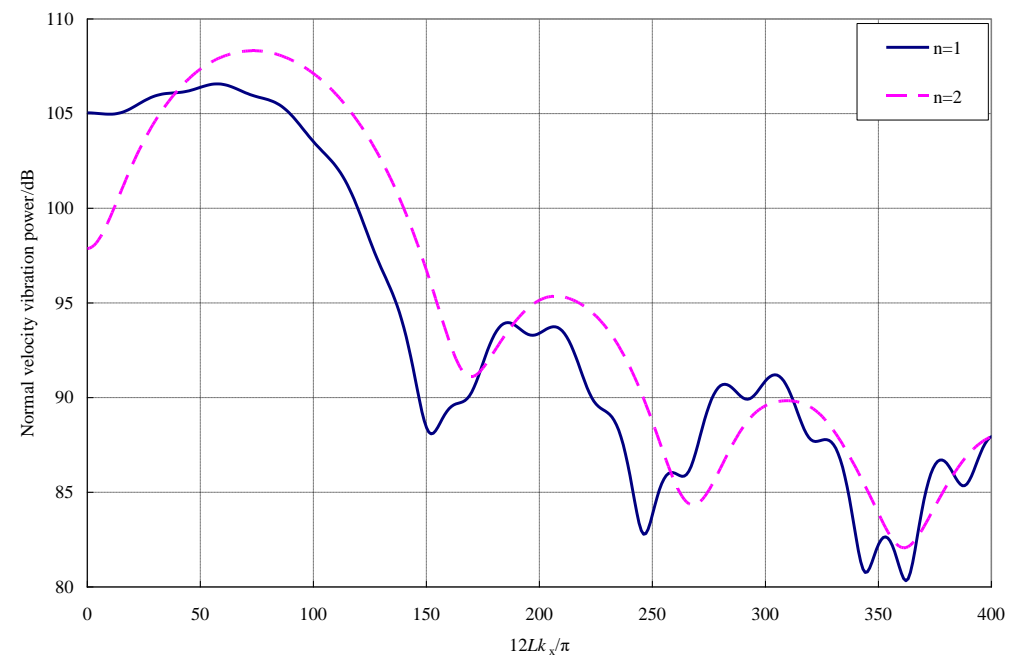

Fig. 16 Normal velocity vibration power wavenumber spectrum in typical frequencies $46 \mathrm{~Hz}$ corresponding to $\mathrm{n}=1,2$ for case 1

It can be seen from Fig. 16 that the vibration of the shell is mainly composed of the structural waves with wavenumbers $(1,60)$ and $(2,76)$. the axial wavelength of the structural long wave $(1,60)$ is approximately equal to one half of the length of the cylindrical shell $(\lambda / l=0.44)$, which is mainly reflected at the end of the shell away from the excitation source; the axial wavelength of the structural short wave $(2,76)$ is approximately equal to one third of the length of the cylindrical shell $(\lambda / l=0.33)$, which is mainly reflected at the end of the shell near the excitation source. The above characteristics of the structure wavelength can also be seen from the vibration mode of the shell, as shown in Fig. 17, where Fig. 17(a) shows the axial vibration mode; Fig. 17(b) shows the circumferential vibration mode near the vibration source, in which $n=1$ order vibration is the main vibration mode; Fig. 17(c) shows the circumferential vibration mode far away from the vibration source, in which $n=2$ order vibration is the main vibration mode.

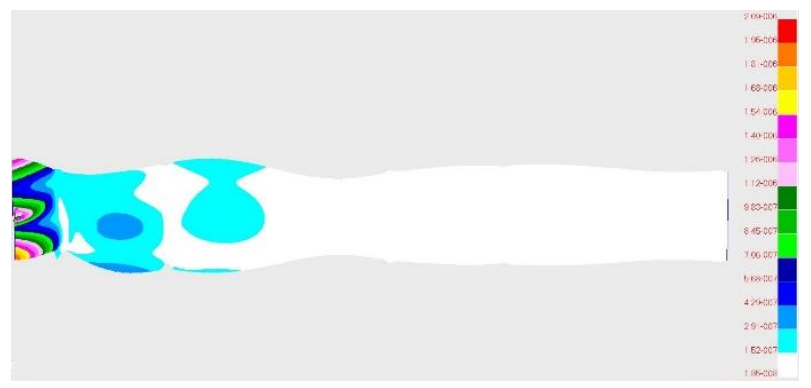

(a)

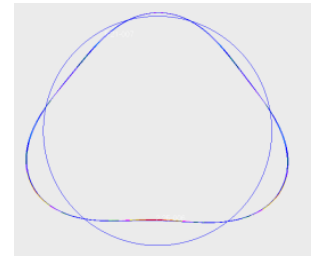

(b)

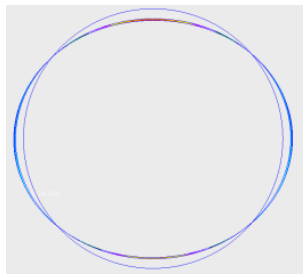

(c)

Fig. 17 Vibration model in $46 \mathrm{~Hz}$ for case 1

(a) Axial vibration mode; (b) Circumferential vibration mode near the vibration source; (c) Circumferential vibration mode far away from the vibration source 
On the basis of the above analysis, it can be seen that under case 1, at each typical frequency, the vibration mode along the axial direction is mainly two to three structural waves.

The method similar to case 1 was adopted to analyze the other four cases. To facilitate comparison, the results of the five cases were collected and summarized, as shown in Table 3. Based on the analysis and conclusions in Section 2.1, 2.2 and the results in Table 3, the following conclusions can be drawn:

- In the low-frequency band, along the axial direction, the contribution of the longer structural transverse wave to the vibration response is dominant.

- Although the magnitude and the direction of axial exciting forces are the same, the action forms are different, so that the vibration forms of the cylindrical shell are different: when the exciting force acts on the side of the cylindrical shell, the bending vibration throughout the cylindrical shell is dominant, therefore, the structural wave is long comparatively, and the amplitude of the spectrum peak of the structural vibration response is large comparatively, such as the cases 1,2 , and 4 ; when the exciting force pair uniformly acts on the cross section of the cylindrical shell, the axial vibration of the cylindrical shell is dominant, therefore, the spectrum peak amplitude of the structural vibration response is reduced, such as the cases 3 and 5. According to the above conclusions, it is necessary to control the long structural bending wave along the axis direction.

- In the low-frequency band, along the circumferential direction, the contribution of the low-order vibration $(n=0,1,2)$ is dominant for the vibration response of the cylindrical shell, so that the low-order vibration in the circumferential direction should be controlled.

- When the exciting force symmetrically acts on the cylindrical shell, $n=0,1$ order vibration is dominant along the circumferential direction, such as cases 3 and 5 , so that the key point of controlling circumferential vibration is to control $n=0,1$ order vibration. The $n=0$ order vibration belongs to breathing vibration, and the breathing vibration can be controlled by strengthening the structure of the cylindrical shell along the circumferential direction.

Based on the above conclusions, in following section 3, the thrust bearing supporting structure of the submarine was redesigned from the perspective of vibration and noise reduction.

Table 3 Comparison of five cases

\begin{tabular}{|c|c|c|c|c|c|c|c|c|c|}
\hline $\begin{array}{c}\text { Case } \\
\text { number }\end{array}$ & $\begin{array}{c}\text { First peak } \\
\text { frequency } \\
(\mathrm{Hz})\end{array}$ & $\lambda / l$ & $\begin{array}{c}\text { Circumferential } \\
\text { wavenumber n }\end{array}$ & $\begin{array}{c}\text { Second peak } \\
\text { frequency } \\
(\mathrm{Hz})\end{array}$ & $\lambda / l$ & $\begin{array}{c}\text { Circumferential } \\
\text { wavenumber } \mathrm{n}\end{array}$ & $\begin{array}{c}\text { Third peak } \\
\text { frequency } \\
(\mathrm{Hz})\end{array}$ & $\lambda / l$ & $\begin{array}{c}\text { Circumferential } \\
\text { wavenumber } \mathrm{n}\end{array}$ \\
\hline 1 & 19 & 0.53 & 1 & 33 & 0.44 & 1 & 46 & $0.44,0.33$ & 1,2 \\
\hline 2 & 19 & 0.41 & 1 & 33 & 0.35 & 1 & 46 & 0.42 & 1 \\
\hline 3 & 32 & 1.5 & 1 & 59 & 2.18 & 0 & & & \\
\hline 4 & 19 & 0.5 & 1 & 33 & 0.45 & 1 & & & \\
\hline 5 & 73 & $1.0,0.6$ & 0,4 & 126 & $0.86,0.1$ & 0,4 & & & \\
\hline
\end{tabular}

\section{Comparison of Two Types of Forms of Thrust Bearing Supporting Structure}

Based on the cylindrical shell shown in Fig. 2, the basic structure of the bow and stern non-pressure-resistant body, internal basic structure, and the thrust bearing supporting structure were constructed to form the basic structure of the submarine, as shown in Fig. 18. There are two types of forms of thrust bearing supporting structure, one is pedestal-type supporting structure which is located on the side of the hull, as shown in Fig. 19, and another is symmetry-type, as shown in Fig. 20. 
The axial exciting force of the propeller, through the transmission shaft, thrust bearing, and pedestal-type supporting structure, acts on the side of the hull, which is likely to cause axial long structural bending waves according to the analysis in Section 2. In order to reduce the structural bending vibration, the structural form of the thrust bearing supporting structure should be redesigned to make the propeller axial exciting force act on the cross-section of the hull symmetrically, meanwhile, the moment caused by the axial exciting force also acts on the cross-section of the hull symmetrically to avoid bending waves of structures with longer wavelength throughout the whole hull range, so that the symmetrically structural form was adopted for the thrust bearing supporting structure ,as shown in Fig. 20. This symmetrically supporting structure is composed of eight I-beams. The distribution of the eight I-beams is symmetrical about the horizontal plane passing through the axis of the cylindrical shell. In order to reduce the circumferential vibration of the shell near the supporting structure, the cross-sectional size of the frames of the shell near the supporting structure was increased.

The eight beams have the same I-shaped cross section, as shown in Fig. 21, and the cross-sectional dimensions are shown in Table 4.

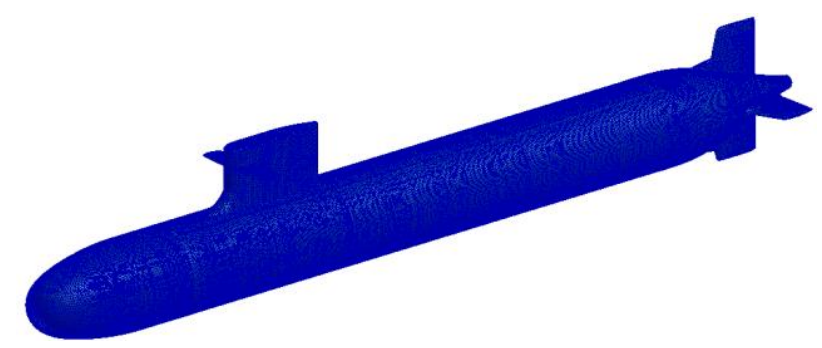

Fig. 18. FE model of submarine

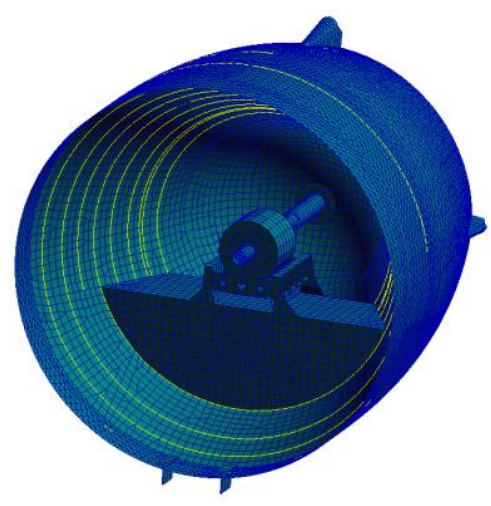

Fig. 19. Pedestal-type thrust bearing supporting system

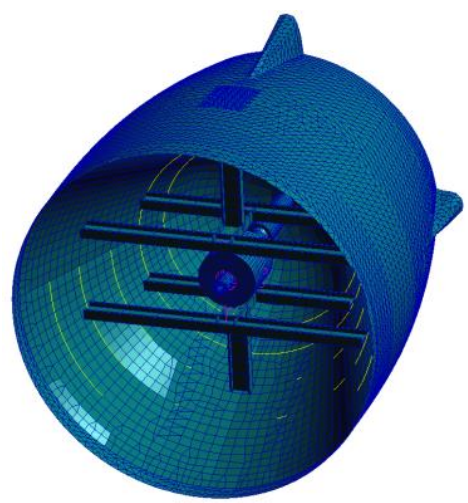

Fig. 10 Symmetric thrust bearing

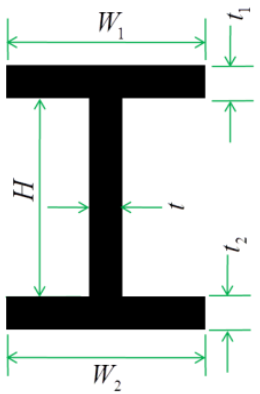

Fig. 21 I-shaped cross section supporting system 
Table 4 Dimension of I-shaped cross section

\begin{tabular}{|c|c|}
\hline Parameter & Value \\
\hline$H / \mathrm{m}$ & 0.28 \\
\hline$W_{1} / \mathrm{m}$ & 0.14 \\
\hline$W_{2} / \mathrm{m}$ & 0.14 \\
\hline$t_{1} / \mathrm{m}$ & 0.03 \\
\hline$t_{2} / \mathrm{m}$ & 0.03 \\
\hline$t / \mathrm{m}$ & 0.02 \\
\hline
\end{tabular}

For the submarine with different thrust bearing supporting structure, the vibration response in the air and the radiated noise in the water are calculated under the action of the propeller axial exciting force. The finite element method, and the coupled method of structural finite element and fluid boundary element [7, 8] was adopted for the numerical calculation. The results are shown in Fig. 22 and Fig. 23, where Fig. 22 shows the frequency curve of the mean square normal velocity of the outer surface of the submarine with the change of the frequency of the exciting force, and Fig. 23 shows the frequency curve of the radiated noise in water with the change of the frequency of the exciting force.

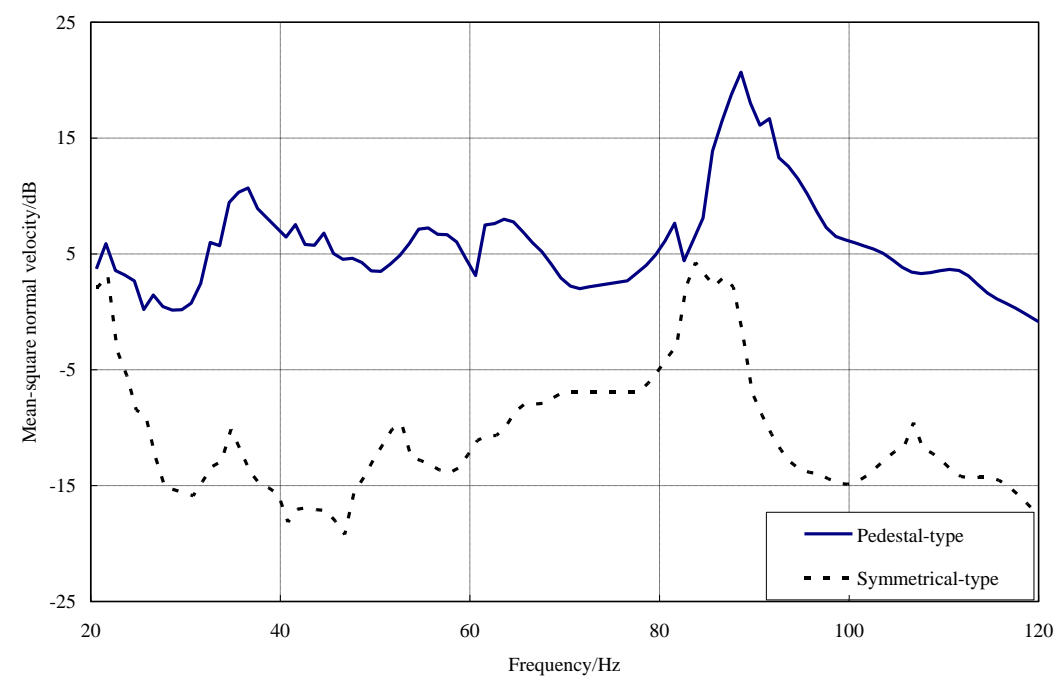

Fig. 22 Mean square normal velocities of submarine outer surface in air

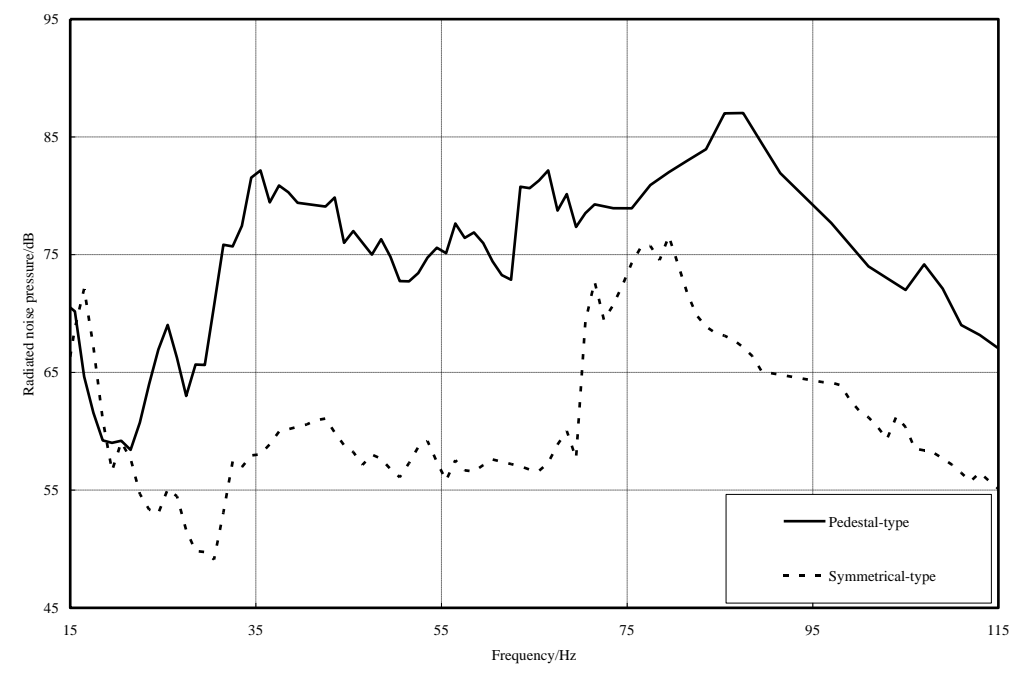

Fig. 23 Radiated noise of submarine outer surface in water 
According to the results in Fig. 22 and Fig. 23, it can be seen that, compared with the pedestal-type thrust bearing supporting structure, the symmetrical-type thrust bearing supporting structure, with the axial stiffness as low as possible, can reduce the vibration and radiated noise of the submarine.

\section{Conclusion}

In this paper, the wavenumber spectrum method was used to analyze the main structural wave components which determine the vibration level of the cylindrical shell, and the following conclusions are drawn:

- The low-order long structure waves make large contribution to the vibration of the cylindrical shell.

- The asymmetry of the axial exciting force and the exciting moment can arouse the long structural waves throughout the cylindrical shell and the submarine, which should be avoided as far as possible.

- The symmetry of thrust bearing supporting structure can largely prevent the axial exciting force from acting unsymmetrically on the hull, which reduces the vibration and radiated noise of the submarine.

The analysis method used in this paper is of practical significance for the study of the mechanism of the vibration and radiated noise of the cylindrical shell and the submarine. The conclusion of this paper can be used to guide the design of the thrust bearing supporting structure of the submarine, therefore, the purpose of the reduction of the vibration and radiated noise can be achieved.

\section{Acknowledgement}

This research was funded by the National Natural Science Foundation of China (Grant number 52071334, Grant number 51579242).

\section{REFERENCES}

[1] Pan C, Sun X, Zhang Y. Vibro-acoustic analysis of submerged ring-stiffened cylindrical shells based on a symplectic wave-based method. Thin-Walled Structures, 2020, Vol.150, pp.1-15. https://doi.org/10.1016/j.tws.2020.106698

[2] SKIDAN O, KLOSNER J.M., BARON M.L. Sound radiation from a cylinder immersed in an acoustic fluid bounded by an elastic half-space. The Journal of the Acoustical Society of America, 1974, Vol. 56, pp. 427-439. https://doi.org/10.1121/1.1903275

[3] Bai Z.G. Vibration and sound coupling behavior and control method of double-layer cylindrical shells. China Ship Scientific Research Center, Wuxi, 2014.

[4] Chang K.Y., Dimaggio F.L. Vibrations of cylindrical shells in a semi-infinite acoustic medium. The Journal of the Acoustical Society of America, 1971, Vol. 49, pp.759-767. https://doi.org/10.1121/1.1912414

[5] Zhou Z, Chen M. Predicting effective moduli of a Z-reinforced core with cavities using a novel theoretical approach and a micromechanics finite element method. International Journal of Mechanical Sciences, 2019, Vol. 161-162. https://doi.org/10.1016/j.ijmecsci.2019.105085

[6] Karczub D G. Expressions for direct evaluation of wave number in cylindrical shell vibration studies using the Flügge equations of motion. Journal of the Acoustical Society of America, 2006, Vol. 119. https://doi.org/10.1121/1.2193814

[7] Merz S., Kessissoglou N.J., Kinns R. Minimization of the sound power radiated by a submarine through optimization of its resonance changer. Journal of Sound and Vibration, 2010, Vol.329, pp.980-993. https://doi.org/10.1016/i.jsv.2009.10.019

[8] Liu W.X., Zhou Q.D. Study on characteristics of radiated noise from the cabin structure with nonuniform subdivision. Journal of Ship Mechanics, 2016, Vol. 20, pp.1045-1058. http://en.cnki.com.cn/Article en/CJFDTotal-CBLX201608014.htm 
[9] Wang P, Li T, Zhu X. Free flexural vibration of a cylindrical shell horizontally immersed in shallow water using the wave propagation approach. Ocean Engineering, 2017, Vol. 142, pp.280-291. https://doi.org/10.1016/j.oceaneng.2017.07.006

[10] Ye W.B., Li T.Y., Zhu X., Chen C. Acoustic radiation of cylindrical shells submerged in the fluid in presence of the seabed or dock. Journal of Ship Mechanics, 2013, Vol. 13, pp.313-325. http://en.cnki.com.cn/Article_en/CJFDTOTAL-CBLX201303016.htm

[11] Li T.Y., Jiang F., Ye W.B., Zhu X. The wave characteristics of the acoustic radiation from cylindrical shells within finite depth from the free surface. Chinese Journal of Ship Research, 2013, Vol. 8, pp.73-79. http://en.cnki.com.cn/Article_en/CJFDTOTAL-JCZG201301012.htm

[12] KWAK M.K. Free vibration analysis of a finite circular cylindrical shell in contact with unbounded external fluid. Journal of Fluids and Structures, 2010, Vol. 26, pp.377-392. https://doi.org/10.1016/j.jfluidstructs.2010.01.006

[13] Yang X.G., Lin L., Bai Z.G., Li B. Sound and vibration transmission characteristic of finite length double cylindrical shells under radial excitation. Journal of Ship Mechanics, 2015, Vol. 15, pp.600-609. http://en.cnki.com.cn/Article_en/CJFDTOTAL-CBLX201505015.htm

[14] Lee S., Vlahopoulos N., Waas A.M. Analysis of wave propagation in a thin composite cylinder with periodic axial and ring stiffeners using periodic structure theory. Journal of Sound and Vibration, 2010, Vol. 329, pp.3304-3318. https://doi.org/10.1016/j.jsv.2010.02.023

[15] Mecitoglu Z. Vibration characteristics of a stiffened conical shell. Journal of Sound and Vibration, 1996, Vol. 197, pp.191-206. https://doi.org/10.1006/jsvi.1996.0525

[16] Photiadis D.M. Localization of helical flexural waves by irregularity. The Journal of Acoustical Society of America, 1994, Vol. 96, pp.2291-2301. https://doi.org/10.1121/1.410101

[17] Marcus M.H., Houston B.H., Photiadis D.M. Wave localization on a submerged cylindrical shell with rib aperiodicity. The Journal of Acoustical Society of America, 2001, Vol. 109, pp.865-869. https://asa.scitation.org/doi/pdf/10.1121/1.5055226

[18] Wang C., Lai J.C. The sound radiation efficiency of finite length acoustically thick circular cylindrical shells under mechanical excitation I: Theoretical analysis. Journal of Sound and Vibration, 2000, Vol. 232, pp.431-447. https://doi.org/10.1006/jsvi.1999.2749

[19] TAN Lu, JI Gang, ZHOU Qidou, et al. Analysis on the vibration and sound radiation characteristics of double cylindrical shells using wave number spectrums. Chinese Journal of Ship Research, 2015, Vol.10, pp. 68-73. (In chinese) http://dx.chinadoi.cn/10.3969/j.issn.1673-3185.2015.06.010

\footnotetext{
Submitted: $\quad$ 08.05.2021. Liu, Wenxi *,wxliu777@163.com,

Accepted:_ 08.07.2021_Guan, Huiren,1064690629@qq.com

Zhou, Qidou, zhouqidou@163.com

Lou, Jingjun,2500896676@qq.com

College of Naval Architecture and Ocean Engineering, Naval University of Engineering, Wuhan 430033, China
} 